\section{Edycaçäa 不}

ARTIGO

\section{Editor}

Alexandre Anselmo Guilherme PUCRS, RS, Brasil

\section{Editor Assistente}

\section{Cibele Cheron}

PUCRS, RS, Brasil

\section{Editores Associados}

Bruno Antonio Picoli

Universidade Federal da Fronteira Sul, Chapecó, SC, Brasil

Pricila Kohls dos Santos Universidade Católica de Brasília, Brasília, DF, Brasil

Renato de Oliveira Brito

Universidade Católica de Brasilia, Brasilia, DF, Brasil

Elisa Ustarroz

PUCRS, Porto Alegre, RS, Brasil

\section{ISSN 2179-8435}

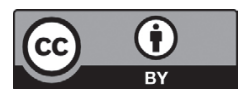

Este artigo está licenciado sob forma de uma licença Creative Commons Atribuição 4.0 Internacional, que permite uso irrestrito, distribuiçăo e reprodução em qualquer meio, desde corretamente citada

\title{
Instruir deleitando: reflexões acerca de abordagens do fenômeno literário em matrizes curriculares de cursos de Letras em São Paulo
}

\author{
Educate with delight: reflections about approaches of the literary phenomenon \\ in syllabus and curricula of courses of Languages in Sao Paulo
}

Fernanda Marques Granato $\oplus^{1}$ Rosane Oliveira Duarte Zimmer $\odot^{2}$

${ }^{1}$ Pontifícia Universidade Católica de São Paulo (PUC-SP), São Paulo, SP, Brasil. ${ }_{2}^{2}$ Pontifícia Universidade Católica do Rio Grande do Sul (PUCRS), Porto Alegre, RS, Brasil.

\section{RESUMO}

$\mathrm{O}$ artigo reflete sobre e explora as abordagens do fenômeno literário em matrizes curriculares, ementas de disciplinas e aulas observadas em duas instituições do ensino superior de São Paulo, mostrando, ao final, uma análise comparatista e uma abordagem do fenômeno literário em sala de aula que busca a retomada da abordagem da gênese e da variabilidade do fenômeno literário. A problemática instigadora foi a abordagem da literatura nos cursos de ensino superior, e como esta leitura conceitual da literatura afeta a prática docente e a formação dos professores. A partir deste estudo de caso, reflete-se acerca da formação do educador literário à luz dos conceitos e abordagens da literatura em sala de aula, tendo como foco o ensino superior. Como hipótese, coloca-se que o conceito de literatura afeta não só a sua abordagem em sala, mas também a leitura realizada do fenômeno literário, transformando o objeto de estudo literário. Quanto ao referencial teórico, temos Compagnon (2009) e Aristóteles (1990) sobre conceito de literatura; Faria (2009), sobre ensino de literatura e formação do leitor literário; Fialho e Fidelis (2008), sobre as primeiras faculdades de Letras no Brasil; Fidelis (1997) e Lajolo (1995) sobre o ensino e a história da literatura; Oliven (2002) e Teixeira (1989) sobre ensino e educação superior no Brasil; Verdi (1980) de ensino de literatura no Brasil; Barthes (2008), sobre história e literatura. Quanto à metodologia de pesquisa, houve o levantamento bibliográfico das referências, seguido do estudo de caso e análise comparada.

Palavras-chave: Literatura. Ensino. Historiografia literária. Fenômeno literário.

\section{ABSTRACT}

This paper reflects upon and explores the approaches of the literary phenomenon in the course curriculum, syllabus and classes from two higher education institutions from Sao Paulo, showing, at the end, a comparative analysis and an approach of the literary phenomenon in the classroom that searches for the restoration of the approach of the genesis and variability of the literary phenomenon. The inquiry of this research was how literature 
is approached in higher education courses, and how this conceptual approach of literature can affect the teaching practice and the training. Stemming from the case study, we reflected upon the teacher formation in light of the concepts and approaches of literature in the classroom, focusing on higher education. As a hypothesis we have the proposition that the concept of literature affects not only how it is approached in the classroom, but also the reading of the literary phenomenon, transforming its object of study. As theoretical references, there was Compagnon (2009) and Aristotle (1990) about the concept of literature; Faria (2009), about the teaching of literature and the reader formation; Fialho and Fidelis (2008) about the first courses of Languages in Brazil; Fidelis (1997) and Lajolo (1995) about the teaching of literature and its historiography; of Oliven (2002) and Teixeira (1989) about teaching higher education in Brazil; of Verdi (1980) about literary teaching in Brazil; of Barthes (2008), about history and literature. Regarding the methodology, there was the bibliographic search of references, followed by the case study and the comparative analysis.

Keywords: Literature. Teaching. Literary historiography. Literary phenomenon.

\title{
Introdução
}

\begin{abstract}
A literar iteratura, como entidade na sala de aula, tem ocupado espaço desde a antiguidade. No Egito Antigo, os escribas eram formados a partir do trabalho com textos literários. Na Grécia Antiga, a função catártica aristotélica conferida aos textos literários tinha importante papel na formação moral e política dos cidadãos. Para os romanos, a retórica, a oratória e a literatura eram saberes fundamentais para o exercício da vida pública, e Horácio, em sua Arte poética, defendia o instruir deleitando, unindo o útil ao agradável. Com o tempo, esse uso dos textos literários na sala de aula passou invariavelmente a ser relacionado ao ensino de idiomas. Ao longo dos anos, a formação humanista foi substituída pela formação científica e, com a evolução dos meios de comunicação, a leitura e a literatura foram relegadas a outro lugar, de menor prestígio. O ensino das línguas passou a ser pautado pelo paradigma linguístico, e a leitura das obras literárias era vazia de significado, com a predominância da historiografia literária. Há poucos anos começou um movimento pelo retorno da literatura na formação dos leitores e pelo dever da escola de trabalhar adequadamente o texto literário, explorando o texto, a sua leitura de mundo e as possíveis relações estabelecidas pelo leitor. Apesar da disciplina ainda existir nas escolas, nos vestibulares e nas faculdades de Letras, o que é entendido por literatura e como o fenômeno literário é abordado em cada época fez com que a instrução de Horácio de "instruir deleitando" (HORACIO, 1823, p. 451-453, v. 343) ${ }^{1}$ fosse esquecida pelo meio do caminho, com apenas as datas, os nomes das obras e dos autores ficando para nós.
\end{abstract}

1 HORACI. Las poesias de Horacio traducidas em versos castellanos com notas y observaciones criticas por Don Javier de Burgos. Madrid: Imprenta de D. Leon Amarita, Plazuela de Santiago, num.1, 1823. 
Para a reflexão a respeito da abordagem do fenômeno literário no ensino superior, objeto pesquisado, foram selecionadas matrizes curriculares de dois cursos de Licenciatura em Letras de Instituições de Ensino Superior (IES). Ementas e aulas de disciplinas de Teoria Literária e de Literatura Portuguesa também foram analisadas. A indagação que motivou a pesquisa e a exploração deste corpus foi a maneira que a leitura conceitual da literatura afeta a prática docente e a formação de professores. Em termos da metodologia de pesquisa, houve o levantamento bibliográfico das referências sobre literatura, ensino, historiografia e abordagens da literatura. Em um segundo momento, passamos à observação de quatro aulas de dois cursos de Licenciatura em Letras em IES de São Paulo. A pesquisadora acompanhou as aulas sem interferir, registrando os acontecimentos, para que fosse possível compreender como se dá a aula cotidianamente, sem a interferência de um agente externo. Cada aula teve a duração média de 3 horas. Para os fins deste estudo, as instituições, os professores, alunos ${ }^{2}$ e disciplinas foram designados da maneira estipulada a seguir de modo a organizar os dados empíricos e de proteger a identidade dos pesquisados ${ }^{3}$ :

- Instituições:

- Instituição I: designada como I1

- Instituição II: designada como I2

- Professores:

- Da I1: P1 e P2.

$\circ \mathrm{Da}$ I2: P3 e P4.

- Disciplinas:

- Literatura Portuguesa: LP1 (da instituição 1) e LP2 (da instituição 2).

- Teoria Literária: TL1 (da instituição 1) e TL2 (da instituição 2).

Quanto à relação entre o observado durante o estudo de caso e as teorias de aprendizagem, modelos pedagógicos e epistemológicos, foi feita uma análise comparativista para explicitar as características de cada disciplina, professor e instituição, com a dinâmica de interação entre alunos e professor. Em relação à necessidade de se pesquisar no meio acadêmico, é importante salientar que para refletir acerca da abordagem da literatura em sala de aula, foi fundamental conduzir esta pesquisa em IES e no meio acadêmico, pois foi possível perceber como as relações entre aluno e professor, entre sujeito e objeto, entre texto literário e concepção de literatura são construídas de maneira a

2 Neste estudo foram representadas suas reflexões em itálico, a fim de distinguir das citações teóricas.

3 As instituições, assim como os professores, não serão nomeados. Isso não compromete os fins deste estudo, que almeja perceber a abordagem da literatura em termos de obras selecionadas e crítica literária que é utilizada em tais cursos de licenciatura em Letras de São Paulo. 
potencializar as oportunidades de ensino aprendizagem de literatura ou de mitigar as possibilidades ali percebidas. Estar no meio acadêmico conduzindo a pesquisa, onde se produz a crítica, é ver o desvelamento de tendências pedagógicas e de seu efeito no ensino da literatura no ensino superior.

No que se refere aos sentidos da pesquisa qualitativa, abordagem adotada diante do tema, temos que o ensino de literatura pode ser observado in loco e pode ser elaborada uma reflexão a partir do real estudado. Quanto aos procedimentos técnicos, escolhemos o modo empírico, colocando lado a lado a visão teórica e os dados coletados da realidade, desenvolvendo a pesquisa em um Estudo de Caso, em que se deu "um estudo exaustivo de um ou poucos objetos, a fim de amplo e detalhado conhecimento" (GIL, 2008, p. 57).

\section{0 que é literatura?}

Em termos de uma definição de literatura, Compagnon (2009) nos traz a teórica, que compreende a literatura como entidade una de valor universal, e a histórica, que percebe a obra como parte de seu contexto de origem. Para o autor, o estudo literário estará necessariamente baseado na tríade teoria, história e crítica. Diante do questionamento da função e utilidade da literatura, Compagnon elege quatro considerações a respeito da pertinência do literário: a capacidade do literário instruir e divertir, além de trazer a imitação que, já dizia Aristóteles (1990), é a maneira por meio da qual o ser humano aprende, por meio da representação dos homens e dos acontecimentos; a libertação que acompanha o literário; a ultrapassagem dos limites da língua testemunhada no literário; e o despoder da literatura, pois ela existe fora do poder, sem função utilitária.

A ideia da ultrapassagem dos limites da língua na literatura é revisitada em Barthes (2008), que coloca o caráter classificatório da língua como limitante das possibilidades de ordenação e construção do enunciado e do que será transmitido. Assim, diz-nos Barthes (2008), a língua é fascista, pois obriga o falante a construir seu discurso a partir de determinado conjunto pré-concebido de sentidos já atribuídos e signos já reconhecidos. Para Barthes (2008), com o literário, é possível revolucionar a linguagem e ouvir a língua fora do poder, criando-se uma performance da representação do irrepresentável por meio da linguagem. Essa visão do literário, pouco vista em sala de aula, será retomada em nossa proposta de abordagem do ensino do literário.

\section{O ensino superior no Brasil: breve histórico}

Antes de adentrarmos a questão do ensino da literatura em instituições de ensino superior, abordemos o histórico do ensino superior no Brasil. De acordo com Fideles e Fialho (2008), os primeiros cursos de nível superior no Brasil 
visavam a formação de médicos. A elite, de acordo com Oliven (2002), realizava o deslocamento até a metrópole para estudar na Universidade de Coimbra, na qual mais de 2.500 nascidos no Brasil se graduaram. Durante o período de regência, após a independência do Brasil, as faculdades tinham prioritariamente os cursos de Medicina, Direito e Engenharia, sendo instituições estruturadas em cátedras vitalícias. Nesse período, foram criados dois cursos de Direito no Brasil: um em Olinda e outro em São Paulo. O catedrático detinha todo o saber de seu campo e ocupava o lugar mais alto da hierarquia.

Conforme Fideles e Fialho (2008), em 1931, com a criação do Ministério da Educação, um estatuto de normas foi estabelecido para as instituições de ensino médio e superior. Diversas universidades se formaram apenas pela incorporação de cursos e faculdades já existentes, por vezes até de esferas administrativas diferentes, compondo um todo descentralizado internamente e centralizado externamente no Ministério, com marcada falta de tradição em pesquisa. Em 1920, foi fundada a Universidade do Rio de Janeiro; em 1927, a de Minas Gerais; em 1931, a Faculdade de Ciências Políticas e Econômicas, que viria posteriormente a se tornar a Pontifícia Universidade Católica do Rio Grande do Sul; em 1934, a Universidade de São Paulo e a de Porto Alegre; em 1946, a Pontifícia Universidade Católica de São Paulo; em 1947, a Universidade do Rio Grande do Sul; e em 1949, a Pontifícia Universidade Católica de Minas Gerais. Em 1969, já existiam 46 IES.

\section{Os primeiros cursos de Letras}

Conforme Teixeira (1989), o primeiro bacharelado em Letras no Brasil foi oferecido pelo Colégio Pedro II, fundado em 1837. Para o autor, foi difícil criar o padrão universitário e por muito tempo contou-se com a vinda de professores estrangeiros para compor os quadros docentes, como no caso da USP. Usualmente, os alunos cursavam três anos para obter o grau de bacharel e um quarto ano para obter a licenciatura. Os primeiros cursos de Letras eram divididos em Letras Clássicas, Letras Neolatinas e Letras Anglo-Germânicas. O curso de Letras da USP tinha como foco a pesquisa e a formação de professores; o da Pontifícia Universidade Católica de São Paulo (PUC-SP), por outro lado, tinha como eixo a pesquisa, a integração, a formação de professores e a independência científica.

\section{O ensino de literatura no Brasil}

De acordo com Verdi (1980), a orientação teórico-crítica postulada por Afrânio Coutinho passou a orientar a leitura historiográfica da literatura que se tornou uma dominante no ensino de literatura. Coutinho (1975), de acordo 
com Verdi (1980), inspirou-se no new criticism estadunidense, pautado pela análise concreta do texto literário, pela desconsideração da condição histórica da literatura, pela rejeição da crítica impressionista e pelo excessivo uso da técnica e do conhecimento cientifico, tendo influenciado a nova crítica, movimento desenvolvido no Brasil marcado prioritariamente pela renovação da crítica. Esta renovação trazia a ideia de que a literatura deveria ser analisada por meio dos seus componentes estéticos, e que apenas um mínimo de contexto sócio histórico era necessário. A partir desta visão e da caracterização dos períodos históricos por meio de normas estilísticas dominantes que dela se seguiu, nasceu a dominante de historiografia de periodização estilística que passou a compreender os movimentos literários como momentos estanques no tempo marcados apenas por determinadas características amorfas que poderiam ser encontradas em certas obras pertencentes àquele período. Essa abordagem persiste ainda hoje em muitas situações de ensino de literatura no Brasil.

\section{Ensino de literatura e história da literatura}

Os fracassos do ensino, segundo Fidelis (2011), são normalmente explicados por meio da abordagem dominante no ensino de literatura a partir da história da literatura, conforme a orientação teórico-crítica de Coutinho (1975), da nova crítica. Dividem-se, então, duas entidades. O ensino de literatura, de um lado. De outro, a abordagem historiográfica, que aborda períodos e autores, impedindo o questionamento e utilizando o literário para se aprender mais sobre um período. Com esta tendência, fossiliza-se a crítica, pois se ensina o que se deve ler e como se deve ler, evitando que outras leituras das obras surjam, diferentes da consagrada. Têm-se, então, o cânone das obras e o cânone da crítica. Esta abordagem, afirma Fidelis (2011), facilita a mensuração e consequente avaliação do aprendizado dos alunos, mas impossibilita que pensemos na literatura e em como ela é concebida e ensinada, para que possamos problematizar a pedagogia da literatura.

\section{Matrizes, ementas e aulas: as IES selecionadas na investigação}

Foram selecionadas duas IES e dois cursos de licenciatura em Letras. O número de IES se justifica pelo período limitado da pesquisa e pela necessidade de equipararmos dados comparáveis. Portanto, duas disciplinas foram escolhidas, a de Teoria Literária, que revelaria a abordagem conceitual da literatura, com as referências da crítica; e a de Literatura Portuguesa, que mostraria a aplicação das teorias nas análises em aulas expositivas, apostilas oferecidas como material de sala e em análises requeridas em trabalhos e avaliações. É importante ressaltar, a respeito das aulas observadas, que "uma escolha de pedagogia inevitavelmente comunica uma concepção do processo de 
aprendizagem e do aprendiz. A pedagogia jamais é isenta. Trata-se de um meio que carrega sua própria mensagem" (BRUNER, 2001, p. 67).

\section{Instituição I}

Em termos do ensino de literatura na matriz curricular do curso de Licenciatura em Letras com habilitação em Inglês e Português da Instituição I, temos que, no primeiro semestre de um curso de sete semestres de duração não há disciplinas de literatura. A disciplina de Teoria Literária acontece apenas no terceiro semestre em caráter geral; no quarto semestre, temos a disciplina de Literatura Portuguesa; no quinto semestre, a de Literatura Brasileira I; no sexto semestre, a de Literatura Brasileira II e a de Literatura Inglesa; no sétimo e último semestre, temos a disciplina de Literatura Norte-Americana e a de Literatura Infanto-Juvenil (eletiva). As disciplinas que focam nas literaturas de língua portuguesa (Brasileira e Portuguesa) têm como contraponto as literaturas de língua inglesa (Norte-Americana e Inglesa), por conta de a habilitação do curso ser em língua inglesa.

Quanto à disciplina de TL1, tem-se uma visão da literatura a partir das transformações históricas, dos gêneros líricos, dramáticos e narrativos, da análise e interpretação de poemas e das correntes críticas; tem como objetivo o desenvolvimento da capacidade de interpretação analítica dos gêneros, focando nas suas características definidoras. A ementa foca na capacidade de analisar a partir das técnicas de interpretação, diferenciando os gêneros e as correntes críticas e reconhecendo a literatura também como ferramenta para se pensar reflexivamente a realidade.

A avaliação ocorre de forma continuada, sob a forma de provas, fichamentos, trabalhos escritos e avaliações semestrais. P1 propõe uma atividade de leitura de um conto, observação de uma aula vídeo e leitura de análise sobre o conto e elaboração de um relatório acerca da interpretação construída acerca do conto na aula e no artigo.

Ao colocar o aluno na posição de comentador de sua análise, esta proposta faz com que este pense sobre a construção analítica realizada pelo professor como um discurso fabricado, possibilitando a percepção por parte do aluno de que ele também pode construir um discurso crítico fundamentado sobre dada obra.

A bibliografia indicada na ementa da disciplina tem como base autores como Antonio Candido, Sábato Magaldi, Massaud Moisés e Hênio Tavares, configurando uma fundamentação no cânone da crítica literária brasileira. Diante da dificuldade apresentada pela maioria dos alunos, P1 propôs que fossem "feitas apresentações sobre os períodos históricos para que a compreensão das obras e as análises dos alunos" (P1, informação verbal) ${ }^{4}$ pudessem refletir uma consideração mais abrangente disso.

4 Depoimento do professor P1 concedido à pesquisadora Fernanda Marques Granato em tal ocasião, na cidade de São Paulo, SP, Brasil, no dia 24 de agosto do ano 2017. 
Em relação à aula observada, o encontro se deu de maneira que a pesquisadora apenas observasse e tomasse notas da aula e não interferisse no andamento da aula. P1 iniciou o período lembrando alguns pontos da teoria de Antonio Candido e corrigindo a atividade sobre ela. A seguir, P1 passa a checar a atividade sobre a teoria de Candido a respeito da interpretação e do comentário na análise de poemas, dando algum tempo para os alunos terminarem de responder. Alguns alunos desejam consultar o livro, e P1 os lembra da importância de citar a fonte no discurso científico, dando um estímulo positivo ao responder que "seria melhor se conseguisse elaborar suas ideias de forma mais autônoma" (P1, informação verbal $)^{5}$, construindo seu raciocínio com autonomia de pensamento. A1 confessa que, durante a atividade, se deu conta de sua "inabilidade de ler de forma interpretativa" (A1, informação verbal) $)^{6}$, dificuldade compartilhada por muitos alunos. $\mathrm{P} 1$ relembra que o "texto referenciado é integral e não foi adaptado ou facilitado" (P1, informação verbal) ${ }^{7}$, e passa a explanação da teoria de Candido. P1 retoma que, "no encontro da teoria literária com as obras, o olhar do crítico e do leitor é dinâmico e faz o objeto, conforme Saussure" (P1, informação verbal) $)^{8}$. 1 relembra a "importância da reflexão acerca da forma de organização dos elementos que compõem o poema para a construção de um sentido" (P1, informação verbal $)^{9}$, levando os alunos ao desenvolvimento de um olhar crítico.

Para P1, na análise, com a micro e macroanálises combinadas,

"Devemos almejar chegar à interpretação, não se prendendo demasiadamente à forma nem ao conteúdo, tomando o cuidado de não tender para o materialismo, uma análise marxista que utilizaria o poema como pretexto para explorar questões externas a ele, nem para o formalismo." (P1, informação verbal $)^{10}$

5 Depoimento do professor P1 concedido à pesquisadora Fernanda Marques Granato em tal ocasião, na cidade de São Paulo, SP, Brasil, no dia 24 de agosto do ano 2017.

${ }^{6}$ Depoimento do aluno A1 concedido à pesquisadora Fernanda Marques Granato em tal ocasião, na cidade de São Paulo, SP, Brasil, no dia 24 de agosto do ano 2017.

7 Depoimento do professor P1 concedido à pesquisadora Fernanda Marques Granato em tal ocasião, na cidade de São Paulo, SP, Brasil, no dia 24 de agosto do ano 2017.

8 Depoimento do professor P1 concedido à pesquisadora Fernanda Marques Granato em tal ocasião, na cidade de São Paulo, SP, Brasil, no dia 24 de agosto do ano 2017.

9 Depoimento do professor P1 concedido à pesquisadora Fernanda Marques Granato em tal ocasião, na cidade de São Paulo, SP, Brasil, no dia 24 de agosto do ano 2017.

${ }^{10}$ Depoimento do professor P1 concedido à pesquisadora Fernanda Marques Granato em tal ocasião, na cidade de São Paulo, SP, Brasil, no dia 24 de agosto do ano 2017. 
P1 "coloca que ambas tendências não devem ser seguidas à risca, mas mescladas, em busca de uma explanação global do poema, de sua forma e seu conteúdo" (P1, informação verbal) ${ }^{11}$. Essa abordagem conduzida por P1 confere um lugar para que o aluno registre o que elaborou, permitindo que

O aluno aja (assimilação) sobre o material que o professor presume que tenha sido significativo para o aluno e que o aluno responda para si mesmo às perturbações provocadas pela assimilação deste material, ou que o aluno se aproprie, neste segundo momento, não mais do material, mas dos mecanismos íntimos de suas ações sobre o material: este processo far-se-á por reflexionamento e reflexão, a partir das questões levantadas pelo professor, e de todos os desdobramentos que daí decorrem (BECKER, 1995 apud PIAGET, 1995, p.6).

P1 passa a uma consideração formal do poema. Diante de um dos poemas trabalhado em sala, A2 questiona: "Um poema escrito no contexto da ditadura só pode ser lido a partir deste ponto de vista?" (A2, informação verbal) ${ }^{12}$, ao que P1 coloca que o recorte do pesquisador e o enquadre do crítico determinará o que você verá, revelando a construção do discurso que se tece na crítica: "O resultado desta sala de aula é a construção e a descoberta do novo, é a criação de uma atitude de busca, e de coragem que essa busca exige” (BECKER, 1995, p. 10).

P1 finaliza essa parte da aula afirmando que, com os estudos literários e as contribuições à Fortuna Crítica dos autores, "cada pessoa verá um aspecto diferente da obra lida e contribuirá com sua leitura de forma relevante" (P1, informação verbal) ${ }^{13}$. A isso se seguem duas apresentações de A3 e A4 a respeito da história geral do século XVIII e sobre a história do Brasil no século XVIII. Neste momento fica patente a dificuldade dos alunos em estabelecer relações com a história e em compreender de forma mais abrangente o fenômeno literário. P1, com a decisão de acrescentar essas atividades avaliativas, tenta suprir uma lacuna que não foi preenchida nos ensinos fundamental e médio, e que deveria compor o repertório dos alunos no nível superior:

${ }^{11}$ Depoimento do professor P1 concedido à pesquisadora Fernanda Marques Granato em tal ocasião, na cidade de São Paulo, SP, Brasil, no dia 24 de agosto do ano 2017.

12 Depoimento do aluno A2 concedido à pesquisadora Fernanda Marques Granato em tal ocasião, na cidade de São Paulo, SP, Brasil, no dia 24 de agosto do ano 2017.

${ }^{13}$ Depoimento do professor P1 concedido à pesquisadora Fernanda Marques Granato em tal ocasião, na cidade de São Paulo, SP, Brasil, no dia 24 de agosto do ano 2017. 
O fato relevante é que ainda há um enorme abismo em relação à didática aplicada no ensino básico para o ensino superior, dificultando o desempenho de alunos que não tiveram ensino de qualidade na educação básica ou que estudaram de forma muito restrita em relação aos conteúdos e métodos de ensino. Diante desse pressuposto, pode-se dizer que a maneira como a maioria dos alunos de escolas públicas chega ao ensino superior não lhes dão condições de acompanhar de forma eficaz os métodos de ensino do professor (ALMEIDA, 2015, p. 4).

Finalmente, podemos dizer que P1 faz o possível para, utilizando a sua formação e seu repertório, promover um espaço de estudo da teoria literária que mescle as vertentes histórica e estética, primando pela qualidade na análise literária e pela construção de um discurso crítico contundente e coerente, apesar das dificuldades patentes dos alunos que, em muitas circunstâncias, são heranças do ensino básico que devem ser supridas no ensino superior e servem como elementos que desaceleram o avanço dos alunos e turvam a sua leitura das obras.

Quanto à disciplina de LP1, ainda na I1, que ocorre no quarto semestre do curso, temos, em sua ementa, os critérios de avaliação de P2, como pontualidade e presença, além das formas de avaliação continuada e dos critérios de avaliação, semelhantes aos exigidos nos exames vestibulares: introdução, desenvolvimento e conclusão; coesão e coerência; respeito à norma culta da Língua Portuguesa e clareza, concisão, objetividade e argumentação pertinente. Aqui percebemos outra falha da educação básica lacunar que deve ser remediada no ensino superior: a dificuldade de leitura e de escrita da maioria dos alunos que hoje vemos no ensino superior.

P2 também propõe visitas a museus e a sua bibliografia está de acordo com a dominante crítica. P2 começa a aula, que foi observada sem interferência por parte da pesquisadora, com uma apresentação de slides sobre o Renascimento, a pintura nesse período e a sua relação com a obra de Luís Vaz de Camões. Em um segundo momento, P2 analisa alguns poemas selecionados. A apresentação sobre o Renascimento começa com a observação de que "este movimento não é caracterizado pelo desaparecimento de Deus da vida dos Homens, pois as pinturas, esculturas e obras de arte em geral desse periodo são constantemente pautadas por temas religiosos" (P2, informação verbal) ${ }^{14}$. Essa abordagem da metodologia expositiva do conteúdo, que coloca o método expositivo como um momento em que o professor pode transmitir o conhecimento, traz o dado de que P2 crê no fato dos alunos serem tábulas rasas e que o conhecimento, teórico, analítico e inclusive cultural, pode ser transmitido do professor, que sabe, para o

\footnotetext{
${ }^{14}$ Depoimento do professor P2 concedido à pesquisadora Fernanda Marques Granato em tal ocasião, na cidade de São Paulo, SP, Brasil, no dia 24 de agosto do ano 2017.
} 
aluno, que nada sabe. Sobre a questão do empirismo e de o aluno ser considerado uma tábula rasa, é importante colocarmos que

O conceito de aprendizagem emergiu das investigações empiristas em Psicologia, ou seja, de investigações levadas a termo com base no pressuposto de que todo conhecimento provém da experiência. Isso significa afirmar o primado absoluto do objeto e considerar o sujeito como uma tábula rasa, uma cera mole, cujas impressões do mundo, formadas pelos órgãos dos sentidos, são associadas umas às outras, dando lugar ao conhecimento. O conhecimento é, portanto, uma cadeia de ideias atomisticamente formada a partir do registro dos fatos e se reduz a uma simples cópia do real (GIUSTA, 1985, p. 26).

A primeira parte da aula, que trata de aspectos teóricos da arte da Idade Média e, posteriormente, da arte renascentista, ocupa dois terços da aula. É interessante notar que, apesar dessa explanação do renascimento ser pertinente se considerarmos a posterior análise de poemas selecionados de Camões, este conteúdo deveria compor o repertório dos alunos antes da entrada no ensino superior. P2, ao realizar esta abordagem, assim como P1, tenta suprir uma lacuna percebida na formação dos alunos que comprometeria a sua aula caso $\mathrm{P} 2$ não tivesse optado por abordar o conteúdo ao longo do curso. Essa lacuna pode ser entendida, dentro da pedagogia diretiva e da epistemologia empirista, que pautam a aula de P2, conforme veremos, como algo que leva à "reprodução do autoritarismo, da coação, da heteronomia, da subserviência, do silêncio, da morte da crítica, da criatividade, da curiosidade" (BECKER, 1995, p. 3) pois o aluno terá a sua lacuna de conhecimento compensada apenas pelo fato do professor ter criado esta abordagem desse conteúdo que julga ser desconhecido pelos alunos; ou seja, os alunos não poderiam conhecê-lo de outra forma.

Na segunda parte da aula, P2 utiliza uma apostila previamente enviada aos alunos, na qual se pode acompanhar os poemas reproduzidos, um breve texto de crítica literária de uma página e um modelo de pergunta e de resposta que poderá ser dada na prova, estruturada e esquematizada de modo a criar um roteiro de resposta para os alunos, como nos cursos pré-vestibulares. Outras estratégias utilizadas que se assemelham ao comportamento dos professores vindos desses cursos são as piadas e as referências ao sexo, que, em um contexto acadêmico, pouco trazem em termos de crescimento qualitativo.

A proposta de pergunta e resposta pode ser relevante, pois é importante o aluno ter clareza dos critérios avaliativos de P2, porém é mais importante que o aluno domine a teoria e os conceitos de tal forma que seja capaz de construir um discurso autônomo a respeito dos poemas e das obras sem necessitar de uma receita pré-determinada, até 
porque em diversas situações mais de uma leitura é possível. Quando o aluno domina a teoria e é capaz de construir seu discurso,

Este conteúdo assimilado, ao entrar no mundo do sujeito, provoca, aí, perturbações, pois traz consigo algo novo para o qual a estrutura assimiladora não tem instrumento. Urge, então, que o sujeito refaça seus instrumentos de assimilação em função da novidade. Este refazer do sujeito sobre si mesmo é a acomodação. É este movimento, esta ação que refaz o equilíbrio perdido; porém, o refaz em outro nível, criando algo novo no sujeito. [...] O novo equilíbrio é mais consistente que o anterior. O sujeito constrói seu conhecimento como conteúdo e como forma (BECKER, 1995 apud PIAGET, 1995, p. 8).

A simplificação da teoria, tanto em relação ao Renascimento quanto à poética de Camões, também é uma maneira de colocar a capacidade de construir um discurso crítico-analítico em um patamar além do aluno que, munido de migalhas, é incapaz de traçar um percurso diferente do já previamente sinalizado. É interessante notar que a disciplina de LP1 ocorre em semestre posterior à de TL1 e, mesmo assim, os alunos necessitam de apoios e revisitas ao cabedal teórico para que o utilizem em suas análises manchadas pela leitura do cânone da crítica, que já lhes fornece $o$ que ler, como ler e como interpretar:

O produto pedagógico acabado desta escola é alguém que renunciou ao direito de pensar e que, portanto, desistiu de sua cidadania e do seu direito ao exercício da política no seu mais pleno significado: qualquer projeto que vise a alguma transformação social escapa a seu horizonte, pois ele deixou de acreditar que a sua ação seja capaz de qualquer mudança (BECKER, 1995, p.3).

Também é pertinente colocar a postura diferente de P1 e P2, dentro da mesma instituição: enquanto um confronta o aluno com a teoria na íntegra e o ensina a pescar, o outro já entrega a tarefa completa e o ensina a reproduzir o discurso já construído. Enquanto em P1 temos uma epistemologia construtivista e relacional, na relação estabelecida por $\mathrm{P} 2$, temos que

Nesta relação, o ensino e a aprendizagem são polis dicotômicos: o professor jamais aprenderá e o aluno jamais ensinará. Como diz um professor ao responder à pergunta "qual o papel do professor e qual o do aluno?": "O professor ensina e o aluno aprende; qual é a sua dúvida?". Ensino e aprendizagem não são pólos complementares. A própria relação é impossível. É o modelo, por excelência, do fixismo, da reprodução, da repetição. Nada de novo pode - ou deve - acontecer aqui (BECKER, 1995, p. 3). 


\section{Instituição II}

$\mathrm{Na}$ I2, em relação ao ensino de literatura na matriz curricular do curso de Licenciatura em Letras com habilitação em Português, com duração de seis semestres, temos, no primeiro semestre, a disciplina de Literatura, Território e Meio Ambiente; no segundo semestre, a disciplina de Teoria Literária: natureza e função da literatura; no terceiro semestre, as disciplinas de Literatura Infantil e Juvenil e a de Teoria Literária: poesia e narrativa; no quarto semestre, as disciplinas de Literatura Comparada e Literatura Portuguesa: prosa e poesia; no quinto semestre, a disciplina de Literatura Brasileira: da poesia do barroco ao modernismo; e, no sexto e último semestre, as disciplinas de Literatura Africana em Língua Portuguesa, de Literatura Brasileira: poesia contemporânea e de Literatura Brasileira: romance.

No que se refere à ementa da disciplina de TL2, há ênfase do estudo literário a partir das transformações ocorridas no âmbito da Teoria Literária, com realização de cortes sincrônicos, leituras e análises de textos teóricos e aplicação de seus conceitos. Como objetivo, a ementa coloca a oferta de instrumental teórico e prático para a leitura e análise do texto literário de modo a aprofundar os conhecimentos. A disciplina trata da poética clássica, da ruptura romântica, do formalismo russo passando pela representação em Platão, pela Poética de Aristóteles, pelos gêneros literários, pelo Romantismo alemão, e por conceitos como arte como procedimento, singularização e estranhamento. A avaliação, que ocorre de forma contínua, perpassa a participação, as resenhas e as provas. A bibliografia está baseada principalmente em Aristóteles, Chklovski, Compagnon, Eco, Iser, Tynianov e Warren e Wellek.

Quanto à aula observada, podemos perceber que tratou da literatura em termos de sua natureza e de sua função, iniciando na Antiguidade Clássica, quando o termo literatura ainda não existia, com as teorizações de Platão, Sócrates e Aristóteles, perpassando a questão da imitação, dos tipos de criador, do mundo inteligível e do mundo sensível, pela arte retórica, arte poética, pela mimese, pela teoria dos gêneros literários, pela gênese da poesia e sua relação com os tipos de imitação, com recortes de obras para exemplificar. P3 busca, ao longo da aula, enfatizar a ideia de se analisar o fenômeno literário com o arcabouço teórico, propondo atividades durante o semestre que tenham suas respostas justificadas com trechos do texto e princípios teóricos. Há estímulo para que os alunos pensem em um recorte da teoria, levando em consideração a sua aplicação, as condições de colocá-la em crise e a construção do pensamento científico sobre o texto literário: "O agir pedagógico (aparece) como movimento questionador que está muito mais preocupado em formular, adequadamente, perguntas do que em buscar respostas certeiras e acabadas" (DALBOSCO, 2007, p. 77).

$\mathrm{O}$ encontro da teoria mais adequada e o desenvolvimento de outras coisas a partir disso, contribuindo com a Fortuna Crítica, é estimulado por P3. O conhecimento, nesta aula, 
Não pode ser concebido como algo predeterminado nem nas estruturas internas do sujeito, porquanto estas resultam de uma construção efetiva e contínua, nem nas características preexistentes do objeto, uma vez que elas só são conhecidas graças à mediação necessária dessas estruturas, e que essas, ao enquadrá-las, enriquecem-nas (PIAGET, 2007, p. 1).

A aula, eminentemente expositiva, conta com grande interesse e participação dos alunos, que perguntam, leem o que foi pedido e tentam analisar os poemas e compreender as teorias. Nesse caso, a abordagem do método expositivo é feita de maneira dinâmica e dialogada, gerando uma resposta positiva dos alunos e a criação de um ambiente adequado para o aprendizado:

Esta sala de aula não reproduz o passado pelo passado, mas debruça-se sobre o passado porque aí se encontra o embrião do futuro. Vive-se intensamente o presente na medida em que se constrói o futuro, buscando no passado sua fecundação. Dos escombros do passado delineia-se o horizonte do futuro; originase, daí o significado que dá plenitude ao presente. [...] para não andar a reboque da história, mas para fazer história; para ser sujeito, portanto (BECKER, 1995, p. 10).

P3 relembra que "a poesia se originou da improvisação de melodias e ritmos" (P3, informação verbal) ${ }^{15}$, assemelhando-se à origem da linguagem, e pode ser percebida como o estranhamento na linguagem, a experimentação e a criação de singularidades, desautomatizadas e sem limites.

Em relação à ementa da disciplina de LP2, temos o estudo das transformações do gênero poesia na literatura portuguesa, com leituras de poemas, estudo das vozes que se colocam como ruptura do passado, estudo da poesia de Camões, Fernando Pessoa, Alexandre Herculano e Eça de Queirós, com ênfase no discurso crítico-reflexivo. P4 propõe o estudo da prosa e poesia portuguesas a partir da leitura e análise de seus textos mais característicos, fazendo uso de uma abordagem do cânone da literatura portuguesa, porém trazendo a pedagogia relacional e a epistemologia construtivista para construir o conhecimento com os alunos, pois possibilita que os alunos interajam com as obras literárias e tirem suas próprias conclusões a partir de suas análises desenvolvidas em sala.

A disciplina passa, ao longo do semestre, pelos seguintes tópicos: a história de Portugal; a poesia Portuguesa, a prosa. Os alunos são avaliados a partir da participação, das provas e dos trabalhos. A bibliografia básica é centrada em Real, Arnaut, Lopondo, Mongelli e Lourenço.

${ }^{15}$ Depoimento do professor P3 concedido à pesquisadora Fernanda Marques Granato em tal ocasião, na cidade de São Paulo, SP, Brasil, no dia 24 de agosto do ano 2017. 
No que se refere à aula observada, em um primeiro momento, houve um seminário realizado por um aluno intercambista, seguido da introdução em forma de pergunta do tema da aula: "O que vocês já conhecem a respeito de Fernando Pessoa?", diz P4 (informação verbal) ${ }^{16}$. Esse momento da aula foi seguido por leituras e análises de poemas selecionados de Pessoa. Em um momento expositivo da aula, P4 realizou uma explanação acerca do que a crítica tem a dizer a respeito de Pessoa, de seu contexto, de sua obra e de suas peculiaridades, como de seus heterônimos, por exemplo, exemplificando com poemas. Os alunos demonstram interesse e participam com análises dos poemas e indicações de leitura.

\section{Análise em perspectiva comparatista}

As duas instituições analisadas, as suas ementas, matrizes e aulas analisadas e observadas, apesar de terem alguns pontos convergentes, divergem em determinados pontos, conforme Quadro 1, adiante.

A partir do Quadro 1, podemos tecer considerações sobre as abordagens do fenômeno literário em cada caso, considerando as semelhanças e as diferenças percebidas nas IES. Tanto a I1 quanto a I2 oferecem cursos de Licenciatura em Letras; ambas contratam professores mestres e professores doutores em suas áreas de atuação; ambas as matrizes contam com no mínimo 6 semestres e com disciplinas de Teoria Literária, Literatura Portuguesa, Literatura Brasileira e Literatura Infanto-Juvenil. Na disciplina de TL, ambas as IES abordam a questão da Fortuna Crítica, do recorte que interfere na maneira em que a obra literária é abordada e de que o olhar, na pesquisa, afeta o objeto estudado. Ambas reforçam a importância da análise interpretativa. Na disciplina de LP, ambas abordam a poética de Camões e de Pessoa. Ambas as IES trazem aulas expositivas baseadas em menor ou maior grau em textos teóricos, análises de excertos de obras literárias e discussões. É importante ressaltar que o método expositivo de apresentação do conteúdo não é em si próprio necessariamente positivo ou negativo, mas que a abordagem do método escolhida por P2 faz com que o caráter expositivo leve a aula a ser vista negativamente apenas como momento de transmissão de conhecimento, prejudicando a possibilidade de utilização positiva dessa metodologia, ou faz com que a aula expositiva seja um momento de se expor a teoria e o material para que os alunos com eles possam interagir e construir conhecimento, potencializando o método expositivo de ensino-aprendizagem e as possibilidades de aprendizagem que ele tem a oferecer.

\footnotetext{
${ }^{16}$ Depoimento do professor P4 concedido à pesquisadora Fernanda Marques Granato em tal ocasião, na cidade de São Paulo, SP, Brasil, no
} dia 23 de agosto do ano 2017. 
Quadro 1 - Síntese da análise: semelhanças e diferenças

\begin{tabular}{|c|c|c|}
\hline & Instituição I & Instituição II \\
\hline Semelhanças & \multicolumn{2}{|c|}{$\begin{array}{l}\text { Matriz: disciplinas de Teoria Literária, Literatura Portuguesa, Literatura Brasileira, Literatura Infanto-Juvenil. } \\
\text { Titulação dos professores: professores doutores e mestres. } \\
\text { Teoria Literária: questão da Fortuna Crítica, do recorte e do olhar que faz o objeto. Análise interpretativa. } \\
\text { Literatura Portuguesa: abordagem da poética de Camões e de Pessoa. } \\
\text { Aulas observadas: expositivas; baseadas em textos teóricos; análises de excertos de obras literárias. } \\
\text { Curso: Licenciatura em Letras }\end{array}$} \\
\hline \multirow[t]{6}{*}{ Diferenças } & $\begin{array}{l}\text { Matriz: disciplinas de Literatura Norte-Americana, Literatura } \\
\text { Inglesa, Literatura Infanto-Juvenil como optativa. }\end{array}$ & $\begin{array}{l}\text { Matriz: disciplinas de Literatura, Território e Meio-Ambiente, } \\
\text { de Teoria Literária dividida em "natureza e função da } \\
\text { literatura" em um semestre e "Poesia e narrativa" em outro } \\
\text { semestre; de Literatura Comparada e a de Literatura Infantil } \\
\text { e Juvenil como obrigatória; de Literatura Africana em língua } \\
\text { portuguesa, de Literatura Brasileira: romance e de Literatura } \\
\text { Brasileira: poesia contemporânea. }\end{array}$ \\
\hline & Duração do curso: 7 semestres & | Duração do curso: 6 semestres \\
\hline & $\begin{array}{l}\text { Teoria Literária: abordagem da teorização de Antonio } \\
\text { Candido; apresentação de seminários sobre a história } \\
\text { do período para compensar formação lacunar dos } \\
\text { alunos. Ausência da teorização de Platão, Sócrates } \\
\text { e Aristóteles, assim como ausência da questão da } \\
\text { gênese da teoria dos gêneros literários, da mimese, da } \\
\text { imitação e da representação, além dos modos de narrar, } \\
\text { predominantemente AUSENTES. }\end{array}$ & $\begin{array}{l}\text { Teoria Literária: abordagem da teorização de Platão e } \\
\text { Aristóteles, da mimese, da imitação, da representação, da } \\
\text { gênese dos gêneros literários; consideração dos conceitos } \\
\text { levantados na Antiguidade Clássica e da natureza e origem } \\
\text { da literatura. Desenvolvimento do pensamento crítico e da } \\
\text { construção de um discurso pautado por princípios teóricos } \\
\text { corroborados pelos textos analisados. }\end{array}$ \\
\hline & Habilitação: Inglês e Português & Habilitação: Português \\
\hline & $\begin{array}{l}\text { Literatura Portuguesa: uso de apostilas; colagem de } \\
\text { teorias; modelo de resposta; abordagem histórica e estética } \\
\text { do Renascimento para compensar falta de repertório dos } \\
\text { alunos; critérios avaliativos de redação que consideram } \\
\text { coesão, consistência argumentativa e coerência. }\end{array}$ & $\begin{array}{l}\text { Literatura Portuguesa: trabalho com o conhecimento } \\
\text { prévio dos alunos; apresentações de seminários sobre } \\
\text { a métrica e a teoria da poesia. Critérios avaliativos que } \\
\text { consideram a capacidade do aluno levar em conta a } \\
\text { tradição e a ruptura na crítica e a construção de um } \\
\text { discurso pela crítica. }\end{array}$ \\
\hline & $\begin{array}{l}\text { Aulas observadas: expositivas; participação com dúvidas. } \\
\text { Alguns alunos estavam presentes pela primeira vez no } \\
\text { semestre. }\end{array}$ & $\begin{array}{l}\text { Aulas observadas: expositivas, porém dinâmicas; alunos } \\
\text { compreendem a extensão e a profundidade dos textos } \\
\text { teóricos e aplicam tal conhecimento nas análises e } \\
\text { considerações que formam o discurso reflexivo por eles } \\
\text { construído. }\end{array}$ \\
\hline
\end{tabular}

Fonte: Elaborado pelas autoras (2017). 
Entretanto, há algumas diferenças: enquanto a I1 traz as disciplinas de Literatura Norte-Americana e Literatura Inglesa, por conta de o curso ser de Licenciatura em Língua Inglesa, e a disciplina de Literatura Infanto-Juvenil como optativa, a I2 traz disciplinas de Literatura, Território e Meio-Ambiente, de Teoria Literária dividida em "natureza e função da literatura" em um semestre e "Poesia e narrativa" em outro semestre; de Literatura Comparada e a de Literatura Infantil e Juvenil como obrigatória; de Literatura Africana em língua portuguesa, de Literatura Brasileira: romance e de Literatura Brasileira: poesia contemporânea, além de trazer disciplinas de Literatura já no primeiro semestre, enquanto I1 só traz disciplinas de Literatura a partir do terceiro semestre. Na I1, o curso tem 7 semestres; na I2, 6 semestres; na I1, a habilitação pode ser de inglês e português, na I2, apenas português. Na I1, na disciplina de TL1, a teorização de Platão, Sócrates e Aristóteles estava predominantemente ausente, com P1 dando ênfase à crítica literária brasileira do final da década de 1970. Por outro lado, na I2, na disciplina de TL2, toda a teoria literária a partir de Platão e Aristóteles estava presente durante todo o curso, além de haver o desenvolvimento do pensamento crítico e da construção de um discurso pautado por princípios teóricos assimilados pelos alunos em seu percurso. Na I1, o uso de apostilas era constante, com colagem de teorias, modelos de resposta, abordagem histórica e estética do Renascimento para compensar a falta de repertório dos alunos e critérios avaliativos de redação semelhantes aos do Exame Nacional do Ensino Médio. Na I2, na disciplina de LP2, as aulas são dinâmicas, com momentos de leitura, momentos de análise e momento de construção elaborada de discurso e aprofundamento crítico da interpretação de cada aluno.

Essas diferenças apontadas são mais do que apenas alguns detalhes a respeito das aulas. Eles delineiam modelos pedagógicos e epistemológicos diferentes, que levam à aplicação de teorias diferentes. No caso da I1, temos, na disciplina LP1, a pedagogia diretiva, na qual o professor, crente no mito da transmissão do conhecimento, acredita que o aluno aprenderá por transmissão de conhecimento do professor para o aluno, que nada sabe; este tipo de pedagogia parte do pressuposto que nada é aprendido pelo professor e que nada é ensinado pelo aluno, algo que é inválido. Por outro lado, na disciplina TL1, da mesma I1, temos a pedagogia relacional, na qual o professor traz o material para a aula, o aluno interage com ele e, de forma dinâmica e dialética, é construído o conhecimento. Os alunos, na pedagogia relacional e epistemologia construtivista, ensinam e aprendem e os professores aprendem e ensinam, construindo continuamente o seu aprendizado. Nessa pedagogia, aluno e professor se relacionam complementarmente, e sujeito e objeto se afetam harmonicamente, com o meio influenciando o indivíduo e o indivíduo influenciando o meio. É interessante notar que dos 4 professores analisados neste estudo de caso, 3 (P1, P3 e P4) podem ser colocados na coluna da Pedagogia Relacional e Epistemologia Construtivista e Teoria de aprendizagem dialética, e apenas 1 professor (P2) pode ser enquadrado na Pedagogia diretiva, epistemologia empirista e repetitiva. Essa maioria pode revelar um caminho profícuo para o ensino de literatura nas IES. 


\section{Considerações finais: proposta de abordagem do literário em sala de aula}

Temos, como proposta de abordagem do literário em sala de aula, a abordagem da literatura que revela os elementos que a configuram, sem, no entanto, limitar a literatura a tais elementos. Almejamos considerar a estética, sem nos limitarmos a algo que não considera a história, pautando movimentos literários apenas por seus elementos determinantes. Queremos considerar a história, sem que dela se faça uma cronologia de autores e obras, datas sem ligação com a época e o que se passava em sua origem. Propõe-se uma aula de literatura que coloque tanto a história quanto a literatura, criando uma mescla de ambas que conduza a uma leitura dinâmica e integral do literário. Nos cursos de licenciatura no Ensino Superior, esperamos poder trabalhar com o texto literário integralmente ao lado do texto teórico sem adaptação ou facilitação, trabalhando para que os alunos aprendam como se dá a construção de um raciocínio, de uma argumentação e de um discurso teórico, crítico, analítico e reflexivo para que cada aluno possa, de forma autônoma, ser o autor de sua própria leitura das obras, tanto ficcionais quanto teóricas. A construção de um caminho na crítica é uma busca de novas leituras a serem desenvolvidas, que podem vir a engrandecer a Fortuna Crítica com novas maneiras de se abordar as obras, redescobrindo o antigo com um olhar novo, como se fosse a primeira vez. Durante o estudo de caso, notou-se que se deve buscar para a prática docente do ensino de literatura em IES a profundidade do conhecimento e do material que pode ser exposto em sala. Porém, este material deve ser colocado para os alunos de modo que estes possam interagir com ele, criando novos significados e novos conhecimentos, assimilando novas estratégias e novos conteúdos, para que não seja um momento estanque sem aprendizado e apenas com reprodução de conteúdo. Os sentidos produzidos durante o registro do estudo, em forma de artigo, revelaram que não se pode pensar no ensino de literatura em termos conteudistas ou arcaicos. Se queremos de fato trabalhar o objeto literário em sala de aula, precisamos deixar que o aluno se aproprie dele e o recrie em seu interior, para então regurgitá-lo criticamente em um discurso construído a partir de sua leitura assimilada sob novas bases.

\section{Referências}

ALMEIDA, Hélio Mangueira de. A didática no ensino superior: práticas e desafios. Estação Científica, Juiz de Fora, n. 14, jul./dez. 2015.

ARISTÓTEleS; HORÁCIO; LONGINO. A poética clássica. São Paulo: Cultrix, 1990.

BARTHES, R. O grão da voz. Tradução de Mario Laranjeira. São Paulo: Martins Fontes, 2004.

BARTHES, R. História ou literatura? In: BARTHES, R. Sobre Racine. Tradução de Ivone Castilho Benedetti. São Paulo: Editora WMF Martins Fontes, 2008. 
BARTHES, R. Aula. Tradução de Leyla Perrone-Moisés. São Paulo: Cultrix, 2004.

BECKER, F. Modelos Pedagógicos e Modelos Epistemológicos. In: SILVA, L. H.; AZEVEDO, J. C. (org.). Paixão de Aprender II. Petrópolis: Vozes, 1995.

BECKER, F. A origem do conhecimento e a aprendizagem escolar. Porto Alegre: Artmed, 2003.

BECKER, F. O que é o construtivismo? São Paulo: FDE, 1994, p. 87-93. (Série Ideias, n. 20).

BRUNER, Jerome. A cultura da educação. Porto Alegre: Artmed, 2001.

COMPAGNON, Antoine. Literatura para quê? Tradução de Laura Taddei Brandini. Belo Horizonte: Editora UFMG, 2009.

DALBOSCO, Claudio A. Pedagogia filosófica: cercanias de um diálogo. São Paulo: Paulinas, 2007.

FARIA, V. F. S. de. O ensino de literatura e a formação do leitor literário: entre saberes, trajetórias de uma disciplina e suas relações com os documentos oficiais. Revista Iberoamericana de Educacíon, v. 49, n. 7, 25 jun. 2009.

FERREIRO, Emilia; TEBEROSKY, Ana. Psicogênese da Língua Escrita. Porto Alegre: Artes Médicas, 1985.

FIALHO, D. da S.; FIDELES, L. L. As primeiras faculdades de Letras no Brasil. Revista História do Ensino de Línguas no Brasil, Helb, ano 2, n.2, jan./jun. 2008.

FIDELIS, F. C. O ensino da literatura e a história da literatura: a mocinha e a vilã? In: SEMINÁRIO INTERNACIONAL DE HISTÓRIA DA LITERATURA, 9., 2011, Porto Alegre. Anais [...]. Porto Alegre: EDIPUCRS, 2011. https://doi.org/10.22456/21770018.2113

GIL, Antônio Carlos. Métodos e técnicas de pesquisa social. 6. ed. São Paulo: Editora Atlas, 2008.

GIUSTA, A. da S. Concepções da aprendizagem e Práticas Pedagógicas. Educ. Rev. Belo Horizonte, v. 1, p. 24-31.

KOTHE, F. O cânone colonial. Brasília, DF: Editora da UnB, 1997.

LAJOLO, M. Literatura e história da literatura: senhoras muito intrigantes. In: MALLARD, L. (org.). História da Literatura. Ensaios. Campinas: Editora da Unicamp, 1995. https://doi.org/10.17771/pucrio.acad.8380

LAJOLO, M. No jardim das Letras, o pomo da discórdia. Disponível em: www.unicamp.br/iel/memoria/Ensaios/pomo.htm. Acesso em: 10 nov. 2017. 
OLIVEIRA, L. E. M. de. A historiografia brasileira da literatura inglesa: uma história do ensino do inglês no Brasil (1809-1951). Dissertação (Mestrado em Teoria Literária) - Instituto de Estudos da Linguagem, Universidade Estadual de Campinas, Campinas, 1999. https://doi.org/10.20396/sinteses.v0i7.11376

OLIVEIRA, L. E. M. de. A instituição do ensino das Línguas Vivas no Brasil: o caso da língua inglesa (1809-1890). 2006. 373 f. Tese (Doutorado) - Programa de Estudos Pós-Graduados em Educação: História, Política, Sociedade, 2006. https://doi. org/10.23925/2176-2767.2019v64p362-370

OLIVEN, A. C. Histórico da educação superior no Brasil. In: SOARES, M. S. A. (org.). A educação superior no Brasil. Porto Alegre: Unesco, 2002.

PIAGET, Jean. Epistemologia genética. Tradução de Álvaro Cabral. 3. ed. São Paulo: Martins Fontes, 2007.

PIAGET, Jean. O juízo moral na criança. 4. ed. São Paulo: Summus, 1994.

PIAGET, Jean. O nascimento da inteligência na criança. 4. ed. Rio de Janeiro: Guanabara, 1987.

SOUZA, R. A. de. O império da eloquência: retórica e poética no Brasil Oitocentista. Rio de Janeiro: Eduerj, 1999. https://doi.org/10.18309/anp.v1i8.358

TEIXEIRA, A. Ensino Superior no Brasil: análise e interpretação de sua evolução até 1969. Rio de Janeiro: Fundação Getúlio Vargas, 1989.

VENTURA, R. História e crítica em Silvio Romero. In: MALLARD, L. (org.). História da literatura. Ensaios. Campinas: Editora da Unicamp, 1995.

VERDI, Eunaldo. O ensino de literatura no Brasil. Revista Travessia, Florianópolis, n. 1, 1980.

Recebido em: 11/4/2019.

Aprovado em: 20/12/2019

Publicado em: 17/4/2020.

Endereço para correspondência:

Fernanda Marques Granato

Pontifícia Universidade Católica de São Paulo

Rua Monte Alegre, Ed. Reitor Bandeira de Mello, 4ㅇandar, sala 4E-03 - Perdizes

05014901, São Paulo, SP, Brasil 


\section{Autoras:}

Fernanda Marques Granato

Doutoranda em Literatura e Crítica Literária pela Pontifícia Universidade Católica de São Paulo (PUC-SP) e Doutoranda visitante na

Universidade de Sheffield (Inglaterra). Mestre em Literatura e Crítica Literária da Pontifícia Universidade Católica de São Paulo (PUC-SP),

tendo Especialização em Docência no Ensino Superior pela Pontifícia Universidade do Rio Grande do Sul (PUCRS).

Orcid: http://orcid.org/0000-0002-3414-6732

E-mail: femarquesgranato@gmail.com

\section{Rosane Oliveira Duarte Zimmer}

Doutora e Mestre em Educação pela Pontifícia Universidade Católica do Rio Grande do Sul (PUCRS), RS, Brasil. É Professora da Faculdade de Tecnologia do Cooperativismo (ESCOOP) e da Pontifícia Universidade Católica do Rio Grande do Sul (PUCRS).

Orcid: http://orcid.org/0000-0002-5860-9754

E-mail: rosane.zimmer@pucrs.br

Endereço: Pontifícia Universidade Católica do Rio Grande do Sul - Escola de Humanidades

Av. Ipiranga, 6.681, Prédio 40, sala 201 - Partenon

97010-082, Porto Alegre, RS, Brasil 